\title{
Readers of English Literature Confronting Quiet Members with Critical Literacy in the Act of Mentoring
}

\author{
Maryam Hessaby Dehbaneh \\ Alzahra University, Tehran, Iran \\ Narjes Banou Sabouri \\ Payame Noor University, Tehran, Iran \\ Javad Ghamkhar Saravani \\ Guilan University, Tehran, Iran
}

\begin{abstract}
In response to many years of a one-way teacher-oriented teaching approach in Iran, there have been some attempts in research to identify young learners as resourceful learning material themselves. Over a period of two semesters, the researchers as teacher-researcher and co-teacher full-time participant observer explore the diverse ways for inviting thirty English Literature majors to voice their own spontaneous learning challenges in reading English literature through mentorship; and characteristics of a popular mentor in critical reading practice and the ways in which a mentor may share her voice with mentees. For this purpose, a qualitative case-study methodology is conducted at Alzahra University (the only-woman university in Iran) for an in-depth understanding of the language and act of reading when Iranian women English literature readers participate in a mentorship interaction. The findings indicated that the mentors/mentees and the teacher create a subtle relationship throughout the semesters by sharing how to read and search for literary texts; how to review literary texts after hearing one another's writing styles; how to voice their critiques with courage; how to overcome competition; and how to invite quiet members to their circles.
\end{abstract}

Index Terms - readers of English literature, critical literacy, quiet members, resourceful mentors, dyadic mentoring

\section{INTRODUCTION}

According to Larson and Marsh (2005), the concept of critical literacy, although rooted in the tenets of critical theory propounded by the Frankfurt school at the beginning of the twentieth century, came to the fore with the work of Paulo Freire mid-century. A view of literacy from a socio-cultural theory of learning (Perez, 2004) considers and seeks to understand the cultural context within which the readers have grown and developed. Critical literacy is an instructional approach that engages students in reading the world and the word, by interrogating texts and discourses inside and outside classrooms (Hart, 2006). It seeks to understand how learners interpret who they are in relation to others, and how they have learned to process, interpret, and encode their world (Perez, 2004). Thus, students need to talk about themselves and also the text to express their worldviews.

Critical literacy is "an activity that reconstructs and develops all parties involved, pulling teachers forward as well as students" (Shor, 1999, Ghahremani \& Kafshgarsouteh, 2011); and it provides students with the opportunity to look critically at literature and question what they are reading (Heimbueger, 2005, cited in McLaughlin \& DeVoogd, 2004; Masny \& Ghahremani, 1999). "Critical Literacy helps teachers and students expand their reasoning, seek out multiple perspectives, and become active thinkers" (Ghahremani \& Mirhosseini, 2005). Learners as the rich source of material can inspire each other to share literacy in classroom.

According to Cazden, (1988) and Tharp (1994) from Freire's point of view learners assume an active role of creative participation. The very act of participation transforms aspects of the social practices or the meaning of literacy. Teachers and peers can shape literacy discussions through collaboration (mentoring); those informal conversations, questions, and comments that provide frameworks for the cognitive processes to be used with the reading activity (cited in Perez, 2004). Paulo Freire (1993) emphasizes the importance of collaboration between teachers and students as a critical factor in evaluating the world in a reflexive manner. Scribner and Cole (cited in Perez, 1981) pointed out that literacy is not just a simple kind of reading but applying this knowledge counts in particular context for specific purposes (p. 236). Fasheh (n.d.) in his enlightening discoveries commented that "a group that wants to be involved in working on literacy, needs to unlearn dominant values, and discuss values that it would like to be guided by in the community". In this view, students have the full capacity to take on their classmate's responsibility in learning. 
Dyson $(1984,1993)$ claimed that learners need to talk about what they are doing as they acquire literacy, and they need to talk with their teachers and peers, and indeed with themselves, as they work their way through reading tasks (cited in Perez, 2004). "In learning to read, learners construct definitions of themselves and their relations with parents, siblings, teachers, and peers ... [they] strive both to be counted as members of social groups and to be recognized as unique individuals" (Solsken, 1993, p. 9, cited in Perez). Freire (1970) stressed the importance of reading the world before reading the word; within the social contexts of community literacy, children learn to read the world and learn to read the word in service to reading the world. Sheridan $(2000$, p.109) reminds us that "Literature is also a powerful means of challenging the way in which the world is constructed". To go further, it is important to remember that literature reflects real life, but it is not real life.

Literature cannot replace rich multisensory experiences that provide the best basis for reading. Still they believe literature can enrich concepts which learners are developing in real life. Some researchers garnered their attention toward the ways to reach literacy. Lewis (2009) found "risk taking critical to literacy success; students must feel confident to guess word meanings, establish relevance, identify point of view, draw conclusions, and make connections with texts" (p. 14). Learners must also have the confidence to share their ideas with others. Sheridan (2000) pointed out that "story reading provides a time for pleasure and success for all students, and provides a context for literacy learning". They put the stories as the main categories of literature in a sense that stories provide a framework for experience. Literature is important personally in many aspects of development. As children read and are read to, "they build up a store of vicarious experiences which become useful in their real lives" (ibid, p.109).

This study is an attempt to seek a) ways of inviting learners to voice their spontaneous changes in reading an English Literature course through mentorship, b) the characteristics of a popular mentor in critical reading practice and the ways in which a mentor can share her voice with the mentees, c) benefits of being a mentor from the perspective of the reader mentor and mentees, and d) changes in critical reading mentoring patterns for every session and pattern for this special kind of participation and negotiation.

\section{METHODOLOGY}

\section{Participants:}

A group of thirty female students of English Literature for their reading I \& II were selected on purpose among whom one is an international scholarship student from Tajikistan. They involved themselves in the mentoring process to share their language experiences via mentoring partnership.

\section{Instruments:}

The learners on their way to practice literacy used a number of instruments in their reading course.

- Observation as a rich participatory act was used full-time

- Interviewing as a contributor to complement the full-time observation

- Field notes and audio-recordings as a moderator to support various phases of observation and interviewing.

- Documents as fruitful written records to strengthen the triangulation

The guiding interview questions will include at least five general themes:

a. The readers' background;

b. Their experience in the reading class with other students;

c. Their experience in the reading class with the teacher;

d. Their critical view toward reading English Literature;

e. Their voice as a critical reader;

On the other angle of data gathering to add to the triangulation, 90 hours of recording (four to six hours per week) was audiotaped while observing the class sessions. The researchers recorded the occasions of interviewing in addition to the class moments of the reading course to keep their voices in store to prevent anything left out. The audio recording of interviewing added up to the time of recording.

\section{Design}

The design selected for this study is qualitative. Qualitative inquiry moves deeper and deeper by going into learner's reading experiences. In order to support the analysis in this study, grounded theory went along with the case study.

The idiographic approach (Gibbs, 2007) in which the individuals (person, place, event, setting, etc.) are treated as a unique case is employed in this study, since this approach looks at each individual differently; it best reflect itself in the examination of case study.

\section{Material}

The students shared their suggested sources online (in their class mail). The syllabus was dynamic and open. Each week, the readers went through the specified selected short story. They were to make sense of the language of the story, language of the critic and a general understanding of the whole reading. In their partnership, they referred to the frequent words of the critic to discover about the position, the ideology of the writer and add them to their glossary (critic codes). During the term while they were discussing the suggested readings and their critiques, they went on with their own desired writers and a search through the literature world to find more about the writers, and were supposed to discover a theme of how they move along their literary narratives through demonstrating their world views and living histories. 
The reading act included:

a. A search for their favorite writers

b. Building a glossary of literary terms

c. Searching about the similar themes of the stories

d. Creating a small, personal encyclopedia of the writers

e. Reading critiques (mine vs. theirs)

f. Asking questions; some suggested are listed as follows:

$\sqrt{ }$ How can I make sense of the story based on my own understanding?

$\sqrt{ }$ How do I make sense of the social condition of the writer and the particularities of his environment which affects his writings?

$\sqrt{ }$ What language elements (words, sentences, etc.) have been used in the story narration?

$\sqrt{ }$ How do the specific language elements explain the writers' particularities?

$\sqrt{ }$ What clues (critical codes) can I find for the social view, the view of character, social structure, social spaces, human relations, determined meanings, inspiration, and.....?

$\sqrt{ }$ What characteristics do I find more in my library and internet searches about the specified writer?

$\sqrt{ }$ Have I ever thought about the reason why I love a special writer or story?

$\sqrt{ }$ How often have I discovered closeness between the critique of the story and my understanding of the same story?

$\sqrt{ }$ How is this related to what I am doing now and who I am? (Is it related to the experiences I have had in other readings I am doing in Persian literature, religious literature, history or other disciplines)?

\section{ANALYSIS \& DISCUSSION}

This was usually the mentor students who often take the first step to invite the quiet members into their circles without hesitation:

Contrary to teacher-fronted kind of classes, the readers had the opportunity to talk and this was rather dialogic. The mentors attended to surroundings and they were very sensitive to what was going on, for example Sarah did attend why Tooba was so silent and she took the further action to invite her.

These senses of sharing took many different forms. There is another mentor who experienced the same case from the other way round.

Yasmin: There are no two equal people, what made people live together is the power of understanding - to respect others while you understand the differences - as soon as you find yourself fine while those who are different as abnormal, that is when living in community would get worse.

Many of the mentors critiqued their teachers who are so simply ignoring the way Literature is:

The mentor students had many different whys for getting connected to the mentees:

Samaneh: As I grew older, I realized that knowledge is not at the top of a gradation but in a sandbox of a nursery school as I was playing with friends and in all the moments we past together...By and by, I understood that I cannot stick to my mothers' apron string anymore so my companies of friends are now the most significant springs of ideas in my life.

Somayeh: I don't want to be very much different to make myself one and alone in a community. In any case of differences, I don't like it be teasing. I don't like to make fun of others. I don't like to elevate myself to down others. I prefer to keep silent but no other ones get displeased.

Ensieh: I used to think that the silent students are clumsy. But now it changed. The very silent one in the class sometimes will wonder everyone like Tooba that she is very simple but very strong; she knows more than others. She understands more I do.

Elham: I don't think the silent learners don't have knowledge on a topic. When I read the writings of Faezeh, I got shocked. I wonder who they are?! They've changed my idea toward the silent members. They are great and very industrious. They are very knowledgeable but they don't put it into word. What I do is to talk of that less that I know.

The mentor learners could clearly outline the way they were:

Zeinab: In the break time, we all laugh together in our sayings. We spent our break time talking to each other rather than sticking to the books like those bookworms. It's nice to have sense of humor but not low comedy that degrades both the speaker and the addressee. Being serious sometimes would crash the interactions. Perhaps this is what attracted you in our class; the atmosphere of our class is not fatal but progressive.

\section{WHAT IS THE POPULAR MENTOR? (RE-NAMING THE TOP ONES)}

The mentee students renamed the top students to the popular one who contributed to the circle as a mentor:

Maedeh: Zeinab is very much humble; there are many top students who are very proud of themselves. They don't answer anyone. They come late and they leave the university early. Zeinab is very different. She has got an encouraging role for everyone.

Paria: At first I was quiet and shy and I didn't want to speak particularly in public because I thought that maybe nobody likes to listen to me, but she (my mentor) helped me believe that we are all equal; it's our right to live, to study, to communicate, to express our feelings, no matter what the other think about you. I consider her a successful girl not 
only in education but also in her own personal life because she is strong and she doesn't let anything disappoints her. She knows how to control her life

Maryam: Yasmin taught me how to do everything well while carrying no claim. I like this behavior in her. She is very humble. She studies very carefully and she is not snob. Many in our class are the same as her.

Somayeh: There is at least one popular person in each circle but Zeinab is very much popular and supportive on the whole. Both the teachers and the students like her. She speaks for the class. She never rejects anyone. In case of failing to learn something, when you go to her, she spends many time explaining. She is different from the 'top' students.

Zeinab as a popular mentor was quiet and created the space for others to talk. She even had a look over the class to see whether anyone needs help or not?! She asked Paria who was sitting three row at rear that is there any problem or not?!

Contrary to what is going on in Iranian schools and universities to promote the sense of 'competition' rather than 'sharing', this critical course of reading connected the mentor learners to the mentees focusing on the 'level of participation' and not 'the amount of talk'. They deformed the concept of academia.

Samaneh: There cannot be anything with scores. Suppose that I have my perfect score, what then?! When I can't answer one who asked me a literary term, then what's the use of these scores?!

Inviting the Quiet members into the circles

Samaneh: At first, we were two groups, it was clearly felt. Students in our group were silent though knowledgeable. They kept silent. The other group was naughty but active. Little by little, the latter group complained that why you are silent?!

Zeinab: In our reading class, some were silent while some others were not. The silent students in those rare instances of talking had nice ideas that were to the point and creative. They were great.

Maedeh: Until recently, we were of two groups: Zeinab's group and ours. It was like a wall drawn between these two groups, but now, we are united in one.

Samaneh: I was part of those who were reluctant to talk even if I knew. My classmates were very much helpful in pushing me to talk...inviting into circles is what I learnt practically from my classmates.

The mentee students sometimes resist talking to have the teacher the message that they are not feeling relaxed since something troublesome is happening:

Ameneh: If I feel relax in a community, I will talk. The conditions are important for me. Sometimes I like to be silent. Some teachers are very sensitive to silent students or when we keep the back seats. Sometimes I intend to be silent deliberately to change the teacher's view. I wonder why those chairs are at the back rear if they are not there to be seated?! I can't really pretend to talk when I don't feel relax.

The critical readers of English in their journey had their genuine version of self:

Ensieh: All of us like to preserve our individuality while participating in groups. No one likes to copy from the others. One of our teachers once told us to make flash card, and said 'please don't copy from each other'. She didn't know that each of my classmates is powerful. We never like to copy. Even the weak member of the class like to show her own weak style that she herself made it.

They believe in respecting each other even if that person is slow. There is no reason for taking pride in 'academic values' since they discard what they are labeled with like 'top student'. They deformed the concept of 'academia' in a sense that it tries to divide the students and to increase the competition. This is the question of why we go to university?! Is that all for learning to gain power to degrade people and to form a wall around us that is debilitative?!

HOW TO INVITE QUIET MEMBERS?

\section{The characteristics of mentors:}

The student mentors invited the quiet members bearing a committed feeling toward each of them. In the research process, the following characteristics were detected common in the mentors:

- Personal \& pedagogical satisfaction: they did not expect anything in return for what they delivered. The top students who take the lead as the mentor students gave support to the quiet members as the mentees and invited them to their circles.

Somayeh: I don't like to talk all the time and if I review what I have in my mind as my belief, what can I add to them then?! To tell and hear the same thing over and over... but if I listen to my friends, I can either learn from them or teach them. This interaction is more useful. I like my class very much. I learnt many things from them.

Atena: I always try to share whatever I know. I did it to my friends and classmates since I have seen its reflection in my own life. I don't want to hide things so that I get the best grades. By the same token, sharing I think is the reward of what I've learnt and if you give it to others, God will make your knowledge more. This is what God will offer as a gift and will further create the opportunity for one to grow.

- Point of departure in providing material: they used their own life stories as the source of readings.

Kimia: I like literature but only when I can have my own comments, rather than any other imposed one. Literature is theoretical beyond any special framework. It cannot be simply judged which idea or critique is true and which is not. And I wonder how teachers score the ideas and the final papers; which answer is true?! ... If I become a teacher, I behave like John Keating in 'Dead Poets Society'. He is my ideal character in teaching. He won't limit the mind of an innocent child with some piece of papers. 
Feeling of responsibility \& bearing internal commitment: They do not wait for any external stimuli for providing support.

Shila: This is all our fault, I think. We have to do something to invite them to the circles. The quiet members should not be given any chance to get used to it.

Taking further steps forward to build rapport: The mentors tried their best to sympathize with the quiet members who often suffer from injustice.

Fatemeh: Atefeh often comes to me and seek my consultation. She shares her problems. All I try is to say about the positive aspect of an issue, e.g., once she said I'm tired of this, what should I do?! I said: you are not alone in this. I also read a story and I had my own comments totally different from that of the teacher while the teacher had different idea. Everyone has its own interpretation. It's natural. I think when a writer is penning a text; he thrust it upon the readers to have their own comments. So there should not be one who says the last word. Yours is true as well as mine. Don't ever think that you must think like the others. Trust yourself and your comments.

- Believing in sustainable \& on-going process of reading and learning. The meaning of 'reading' was re-defined.

Zeinab: If once I get to the point where I experience two days with no difference, it is then that I stopped the act of reading. The act of reading cannot be confined to the paper; these are the frameworks that are problematic and it is as a calamity for the students. These papers will bring you PhD, and academic achievement; if there won't be any outcome, this is where we will ask 'so what?!' this 'so what' of where is this certificate or this degree from has started here: one stands where s/he should not be...

Ensieh: Reading in the first look is a series of dead words. It's waiting for the readers to be alive. When I give them life, they will become part of my life. Different readers would give different meaning and life to the words and this different life will make reading beautiful. Everyone has got its own understanding of a text and would make it somehow different...

Showing their desire to self-disclosure: The mentors were so pleased with the way they were treated as a mentor.

Leila: when I share, I feel like someone trusted me. The feeling like I CAN; I like when I think there is something out there that made them come to me and seek for my assistance. I like this feeling and I do appreciate it.

- Adherence to caring relationship: the mentors were very patient and warm to let the quiet members feel free to share any problem.

Faezeh: She (the mentee) was alone in the corner of the class busy writing her assignment in rush. I came next to her and I said: "I'm free and I have extra time right now, if there is anything I can do for you; please tell me what, then I might be helpful". She looked at me nicely and accepted my assistance.

Managing the time and the impossibilities: The top student as it is renamed to the popular mentor (Zeinab) feel herself like acting the same as the mentee students and never feel pity for the mentees; instead, she let them leave themselves open to their problems. I came across to the following piece of conversation while observing their class time before the teacher starts in:

Soheila: This is very difficult for examination.

Zeinab: Yes, I have the same idea. I summarized it all; I will leave it online (a shared email for reading that Zeinab made it for class).

Soheila: But, it is difficult and too much for exam,

Zeinab: Yes, It is. We have to talk to the teacher to skip some parts for exam.

- Laying different social roles: most of the mentors were learner and teacher at the same time. They started their teaching life outside the university in small schools. For instance, Ensieh is an energetic girl who everyone likes to share her experience with. She is very active with different roles as a play writer, an English teacher and also an active member of a cultural-religious website.

- Inviting silent members: The mentors were very attentive regardless of how their teachers might react.

Maryam: I was late on purpose to seat away from my own friends. They are out there; I liked to sit next to those who were silent. There were clearly two parts in the class, some remained silent for a long period. All the teachers labeled them 'silent' members of the class; I've thought to myself that maybe they are feeling bad....As the Persian poet, Homayi put: 'It is not important if the tree drops the fruits into its own skirt but the further the fruit, the better'.

- Being pioneer in breaking the ice: Some mentors pushed the mentees to voice their ideas after some instances of partnership. Here is how Samaneh encourages Faezeh as the mentee to couch her comment:

Samaneh: (while raising Faeze's hand) excuse me! Excuse me prof. (addressing the teacher) Faeze is going to say something...

Faezeh: (whispering no, no..)

Teacher: Faezeh?

Faezeh: Yes, I actually wanted to say...

- Craving for human science: Reading people and craving for human sciences is the key to be a critical reader and resourceful mentor.

Yasmin: My nature is to seek for human science though I am able to read all other majors; human science is what I feel satisfied with and I find it a good opportunity to go and search for the life of different people to see their lifestyles. I personally believe that no one can get success unless one knows people well. 


\section{The characteristics of mentees:}

Interacting with the quiet members would not be possible if they themselves do not accept the offer to go critically into the reading contexts. Here are the characteristics which are spotted in the mentee students:

- Establishing tolerance of ambiguity:

Ameneh: At first, I was so embarrassed. But I asked myself to be strong reading the text over and over. I knew there must be a way to get out of the situation.

- Seeking equal social status:

Simin: I was quiet but I knew this must no longer last. I had to take the opportunity to find my position and to get where I am.

\section{The Shared characteristics:}

The mentors and the mentees all were found to share the following characteristics:

- Having the concept of dialogic evaluation in mind:

- Ability to discuss critical literacy

- Critiquing Critique

- Reserving no place

- Being the genuine version of themselves

- Building mutual trust and respect

- Voice their critique with courage

Maedeh: since the silent students know as much as the other members of the class, they can be invited by responding to the kind of questions through which they like to talk about their life experiences

Ameneh: I like to share my good experiences with those who value them, humans are like books, each waiting to be read. If there is someone interested to read, I will open myself.

Nastaran: Those who are silent listen better, I think. Thus, they would get everything completely. When I get silent, this is not because I don't know what to say or I don't have any idea but I don't like to interact with the given community so it's better to let me free.

\section{READING FROM THE VIEW OF MENTORS \& MENTEES}

Reading here was beyond a skill; it was an every-day life of readers who perceive language in texts as alive waiting to be discovered. The mentors invited the silent readers to how to read; the dictionary was a disturbing tool to boost creativity. Here the readers learned how to read broadly without using a dictionary.

- Re-authoring the text

- Accepting different acts of reading

- Following no pre-assumption

- Thinking critically on texts

- Reading to write

- Reading to get new experience

- Communicating with white texts

- Believing in sustainable learning

- Believing in metaphysical rules

- Acquiring the power of analysis

- Accepting different social roles in reading

- Deforming 'academia'

Critical readers had the desire for sharing and the mentees also accepted their invitation. They voluntarily liked to share their reading experiences in the class. The mentees were not looked upon as someone with a problem rather the one with ambiguity.

\section{CONCLUSION}

As a teacher, it was always a concern to discover and tackle quiet members. Quiet members in contrast to 'top students' of the class used to have two different positions while in this study we found them both the same. That is, it is discovered how students have the power of mentoring the quiet members by inviting them to read critically.

The resourceful language mentors were selected for their qualities beyond the reading classroom. The learners carried the feeling of accountability \& responsibility toward each other, and they continued mentorship even after they communicated their roles as mentees as well. They changed their learning patterns and started to supervise the other quiet members out of their class setting even after the research course completed. Seeking for human sciences was their shared departing point to study English Literature. They were eager to listen to real-life stories of people and bring them into their literary texts. They regarded their classmates as the source of the material and they voiced their critique with no pre-assumption. The mentor students liked to read everything but with a blank mind. The meaning of some words was deformed like 'academia', 'institution' and 'top student'. They believed in sustainable learning and this is why they could overcome competition and the 'top' student made no further sense; rather, it was popular to be trusted by the mentees. 
The results also showed that the mentors did not downplay the mentees' pain or problem. Doors were opened for mentees to get the opportunity to experience being a mentor as well as a mentee. The quiet readers could get their way into critical literacy inspired by the experience of being a mentee.

What the mentors get out of this is a different perspective toward the meaning of reading seated deeply into life. Mentors practiced critical literacy in a sense that there were no mechanical stimuli to make them feel responsible. This was thoroughly dynamic and on-going that they themselves were generous to ask the mentees "what do they need for reading critically?" Both mentee and mentor students experienced how one can get into the reading process in its broader sense.

The teacher by degrading 'evaluation' focused on the importance of interaction and inspired the mentor students to go and search for mentee students (she did name no one, i.e., no assigning kind of mentoring occurred). The mentoring interaction kept on going to an extent in which the mentee students also experienced being a mentor since the teacher had no priority of who is a mentor and who is a mentee (no one was dearer than the other). She broke the habits first by sitting below the podium; then by breaking the big circles into the smaller ones, she indirectly wanted the learners not to reserve any special place. The importance of quality of presence was emphasized more than the quantity since there was no 'call list' to account for the absentees.

In this study, reading was beyond a skill; it is the every-day life of readers who look at discourses critically. Contrary to the controlled way of practicing mentoring in a great body of literature, we come up to a class in which there was mutual respect for sharing with no expectation. There is also no clear-cut moment to pinpoint that mentoring started from this and came to an end in that point.

Drawn from data, we discovered that reading critically will not be possible if readers themselves are not interested in it. The teacher also created space in a way for the readers that each had the opportunity to share and open herself to the other side of the fence.

Mentors/mentees and the teacher created a subtle relationship throughout the semesters by sharing how to read and search for literary texts; how to review literary texts after hearing each other's writing styles; how to voice their critiques with courage; how to overcome competition; and how to invite quiet members to their circles. Noteworthy to add that, approaching these two theories i.e., mentorship to critical literacy brought us into a new theory: it is usually the case to bring 'reading material into the class' that is like reading is an external entity that is not permitted to be with the learners unless the course of reading is to be held; this journey is the case with taking 'readers into reading' that is to be called: Reader Reading.

The language teachers may usually ask themselves 'what should I teach in this English reading course?!' They are suggested that the readers are into the classroom waiting to be discovered by reading their language experiences as well as literacy ones. The quiet language readers are waiting to be invited rather than being pushed into the 'commonly-used reading material'. Readers Reading is a path to invite the resourceful learners to keep on reading into homes as well as schools.

\section{REFERENCES}

[1] Fasheh, M. (n.d.). A personal journey of an intimate relationship between learning and unlearning. Retrieved July 16, 2011, from sadzaban.com/files/WEEK \%204 \%20 Fasheh.pdf.

[2] Freire, p. (1970).Cultural action for freedom. Cambridge. Harvard Educational Review. United States.

[3] Freire, P. (1993). Pedagogy of the oppressed. The Continuum International Publishing Group Inc., New York.

[4] Ghahremani-Ghajar, S., \& Kafshgarsouteh, M. (2011).Recovering the power inside: A qualitative study of critical reading in an Iranian university. Turkish Online Journal of Qualitative Inquiry, 2(3), 26-39.

[5] Ghahremani-Ghajar, S., \& Mirhosseini, S. A. (2005). English class or speaking about everything class? Dialogue journal writing as a critical EFL literacy practice in an Iranian high school. Language, Culture and Curriculum, 18(3), $286-299$.

[6] Gibbs, G. (2007). Analyzing qualitative data. The Sage Qualitative Research Kit. London: Sage

[7] Hart, S. (2006). Breaking literacy boundaries through critical service learning: Education for the silenced and marginalized [Electronic version]. Mentoring and Tutoring, 14(1), 17-32.

[8] Larson, J., \& Marsh, J. (2005). Making literacy real: Theories and practices for learning and teaching. SAGE Publications Ltd, New York.

[9] Lewis, J. (2009). Essential questions in adolescent literacy. The Guilford Press, New York.

[10] Masny, D., \& Ghahremani-Ghajar, S. (1999). Weaving multiple literacies: Somali children and their teachers in the context of school culture. Language, Culture and Curriculum, 12(1), 72-93.

[11] McLaughlin, M., \& DeVoogd, G. L. (2004). Critical literacy: Enhancing students' comprehension of text: Theory and practice. NY: Scholastic, New York,

[12] Perez, B. (2004). Sociocultural Contexts of Language and Literacy ( $2^{\text {nd }}$ Ed.). Lawrence Erlbaum Associates, New Jersey.

[13] Sheridan, C. (2000). Children's literature and literacy learning. In C. Barratt-Pugh, \& M. Rohl (Ed.), Literacy Learning in the Early Years. Crows Nest: Allen \& Unwin.

[14] Shor, I. (1999). What is critical literacy? In I. Shor, I. \& C. Pari (Eds.), Critical Literacy in Action: Writing Words, Changing Worlds.1-30, Portsmouth: Heinemann. 
Maryam Hessaby Dehbaneh was born in 1985 in Rasht. She is an AM holder of TEFL from Alzahra University. When she was 19, she experienced publishing her first book 'Let's Write English'. She enjoyed learning and researching independently as an undergraduate in Translation. Her areas of interest are Critical Literacy in the Iranian context, ESP, Material Development, Discourse and CALL. She developed her career in Volleyball field, and as the press delegate of Iran took membership in Asian and World Confederations (AVC \& FIVB).

Narjes Banou Sabouri is the assistant professor of Linguistics. She is also a faculty member in Department of Linguistics at Payam-e Noor University of Rudsar, Guilan, Iran. She has taught English courses for over eight years. She has delivered many international articles in teaching and linguistics in credentialed journals.

Javad Ghamkhar Saravani was born in 1986 in Rasht. As a school teacher, he expanded his teaching experience both in Persian and English literature with focus on culture and local lifestyle. In his academic journey, he questioned the status quo and challenged the schooling system. 